\title{
Electrocatalytic Oxidation of Dinitrogen to Nitric Acid via Direct Ten-Electron Transfer Using Manganese Phthalocyanine
}

Ashadul Adalder ${ }^{1}$, Sourav Paul ${ }^{1}$, Biswajit Ghorai ${ }^{1}$, Samadhan Kapse ${ }^{2}$, Ranjit Thapa ${ }^{2}$, Abharana N., ${ }^{3}$ and Uttam Kumar Ghorai ${ }^{1, *}$

${ }^{\mathbf{1}}$ Department of Industrial Chemistry \& Applied Chemistry, Swami Vivekananda Research

Centre, Ramakrishna Mission Vidyamandira, Belur Math, Howrah, 711202, India

${ }^{2}$ Department of Physics, SRM University - AP, Amaravati, Andhra Pradesh, 522240, India

${ }^{3}$ Atomic \& Molecular Physics Division, Bhabha Atomic Research Centre, Mumbai, 400085, India

\section{Corresponding author:}

*Email: uttam.indchem@vidyamandira.ac.in

ABSTRACT: Ammonia produced through the energy intensive Haber-Bosch process, undergoes catalytic oxidation for the manufacture of commercial nitric acid in the age-old Ostwald process. This two-step energetically non-viable industrial process demands the quest of an alternative single step electrocatalysis from the last century. The quest ends up in optimism when we unravel a ten-electron pathway associated with electrochemical dinitrogen oxidation reaction $\left(\mathrm{N}_{2} \mathrm{OR}\right)$ to nitric acid by manganese phthalocyanine ( $\mathrm{MnPc}$ ) hierarchical nanostructures (HNs) at STP. The catalyst delivers nitric acid yield of $720 \mu \mathrm{mol} \mathrm{h}^{-1} \mathrm{~g}^{-1}$ cat @ $1.9 \mathrm{~V}$ vs. RHE and F.E. of $17.32 \%$ @ $1.7 \mathrm{~V}$ vs. RHE in $0.05 \mathrm{M} \mathrm{HCl}$. The local co-ordination environment $\left(\mathrm{Mn}-\mathrm{N}_{4}\right)$ during electrocatalysis process is ensured by the XAFS study. DFT based calculations express that the $\mathrm{Mn}$ site of $\mathrm{MnPc}$ is the main active center for nitrogen adsorption for $\mathrm{N}_{2} \mathrm{OR}$, suppressing the OER. 
Keywords: Manganese phthalocyanine, nitrogen oxidation, Ostwald process, nitric acid, green synthesis

Introduction: Artificial nitrogen fixation utilizing chemical transformation technology of nitrogen based compounds, such as nitric acid $\left(\mathrm{HNO}_{3}\right)$, using green chemistry route is one of the prime demand of present time ${ }^{1}$. Nitric acid is a major key player in various industries and an extremely important chemical constituent of the nitrate based fertilizers for plant growth, gun powder, and explosives ${ }^{2}$. Commercial nitric acid is prepared by the 120 year old Ostwald process where $\mathrm{NH}_{3}$ gets oxidized in presence of catalyst at high temperature $\left(400-600^{\circ} \mathrm{C}\right)$ and pressure (15-25 MPa). This process is extremely energy demanding and produces extravagant amount of greenhouse gases $\left(\mathrm{CO}_{2}\right)$ into the atmosphere ${ }^{1}$.To produce $\mathrm{NH}_{3}$ in the industrial scale, HaberBosch process is employed where raw materials $\left(\mathrm{N}_{2} \& \mathrm{H}_{2}\right)$ are treated at high temperature $(700 \mathrm{~K})$ and pressure $(150 \mathrm{~atm})$. This process consumes $1 \%$ of the total global energy and produces 1.9 metric ton of greenhouse gas $\left(\mathrm{CO}_{2}\right)$ per metric ton of $\mathrm{NH}_{3}$ synthesis ${ }^{1,3}$. Therefore, the deletion of the dual step $\mathrm{HNO}_{3}$ synthesis method forms a mandatory requirement to address the issue and provide an alternate sustainable solution yet catering to the demand of the market. Electrocatalytic dinitrogen oxidation reaction $\left(\mathrm{N}_{2} \mathrm{OR}\right)$ using electrocatalyst under ambient conditions is an optimistically promising alternative to develop sustainable nitrate product using various heterogeneous catalysts such as $\mathrm{Ru} / \mathrm{TiO}_{2}, \mathrm{Pd}-\mathrm{MXene}, \mathrm{ZnFe}_{\mathrm{x}} \mathrm{Co}_{2-\mathrm{x}} \mathrm{O}_{4}, \mathrm{Fe}-\mathrm{SnO}_{2}, \mathrm{Nb}_{2} \mathrm{O}_{5-\mathrm{x}}$, Pd-s PNSs, etc. ${ }^{4-14}$. Electrocatalytic $\mathrm{N}_{2}$ oxidation processes follow a two-step pathway. In the first step, $\mathrm{N}_{2}$ reacts with $* \mathrm{O}$ to form $\mathrm{NO}^{*}$ intermediate and followed by the reaction of $\mathrm{NO}^{*}$ with $\mathrm{H}_{2} \mathrm{O}$ and $\mathrm{O}^{*}$ to form the nitrates ${ }^{12}$. Simultaneously, competing four electron oxygen evaluation reaction (OER) takes place in the first stage which is the rate limiting step. From the partial Pourbaix diagram for $\mathrm{N}_{2}-\mathrm{H}_{2} \mathrm{O}$ system, it is noted that $\mathrm{N}_{2} \mathrm{OR}$ is more favorable for nitrate 
synthesis over OER while $\mathrm{pH}$ is greater than $1.3^{1,16}$. Thus, strategic design with precise selection of $\mathrm{N}_{2} \mathrm{OR}$ electrocatalyst is extremely important to sufficiently suppress the OER and promote the $\mathrm{N}_{2} \mathrm{OR}$ in the same potential window. Recently metal phthalocyanines $(\mathrm{M}=\mathrm{Co}, \mathrm{Ni}$ and $\mathrm{Fe}$ ) have showcased as high performance NRR electrocatalyst for $\mathrm{N}_{2}$ fixation to $\mathrm{NH}_{3}$ owing to its metal centre based $\mathrm{M}-\mathrm{N}_{4}$ active sites ${ }^{15-17}$. In addition to that, manganese phthalocyanine (MnPc) also does structurally possess $\mathrm{Mn}-\mathrm{N}_{4}$ active sites ${ }^{18}$, and its superiority for electrochemical $\mathrm{N}_{2} \mathrm{OR}$ is yet to be unraveled by the scientific fraternity.

In this regard, Prof. Nørskov and co-workers ${ }^{19}$ have developed a theoretical model to understand the probable reaction mechanisms at the molecular level of $\mathrm{N}_{2}$ oxidation to direct $\mathrm{HNO}_{3}$ via ten electron transfer process $\left[\mathrm{N}_{2(\mathrm{~g})}+6 \mathrm{H}_{2} \mathrm{O}_{(\mathrm{l})} \rightarrow 2 \mathrm{HNO}_{3(\mathrm{l})}+10 \mathrm{H}^{+}+10 \mathrm{e}\right]$ with the reaction of $\mathrm{N}_{2}$ and $* \mathrm{OH}$. They have not only studied the reaction pathway but also have shown the clearer understanding of the competition reaction between OER and $\mathrm{N}_{2} \mathrm{OR}$ on the oxide surface. Inspired by their theoretical research work on $\mathrm{N}_{2} \mathrm{OR}$, we have demonstrated MnPc $\mathrm{HNs}$ as $\mathrm{N}_{2} \mathrm{OR}$ electrocatalyst to synthesize nitric acid, through the ten electron reaction pathways. The MnPc HNs delivers a nitric acid yield rate of $720 \mu \mathrm{mol} \mathrm{h}^{-1} \mathrm{~g}^{-1}$ cat @ $1.9 \mathrm{~V}$ vs. RHE and F.E. of $17.32 \%$ @ $1.7 \mathrm{~V}$ vs. RHE in $0.05 \mathrm{M} \mathrm{HCl}$. The nitric acid yield was quantitatively estimated by ion chromatographic method. Isotopic labeling experiment has been further carried out to decipher the actual source of nitrogen in nitric acid by the ${ }^{15} \mathrm{~N}$-nuclear magnetic resonance $\left({ }^{15} \mathrm{~N}-\right.$ NMR). DFT computations substantiate the above study with identifying the prime active centers for $\mathrm{N}_{2}$ adsorption in MnPc. We have further confirmed that the $\mathrm{N}_{2} \mathrm{OR}$ is a dominant reaction over OER in the same potential on both Mn and C sites in MnPc catalyst. 


\section{Results and discussion}

Theory guided catalyst design for $\mathbf{N}_{2} \mathrm{OR}$ : The reaction mechanism, overpotential and active sites of electrochemical $\mathrm{N}_{2}$ oxidation reaction $\left(\mathrm{N}_{2} \mathrm{OR}\right)$ are investigated by using density functional theory based method. Firstly, we demonstrate the complete free energy profile of ten electrons $\mathrm{N}_{2} \mathrm{OR}{ }^{19}$ considering each intermediate on $\mathrm{MnPc}$ as shown in Figure 1b. The other possible pathways for $\mathrm{N}_{2} \mathrm{OR}$ are shown in Figure SI. The pathways we considered are alternating (simultaneous oxidation of both $\mathrm{N}$ atoms) and distal (one by one $\mathrm{N}$ atom oxidation) at applied potential $\mathrm{U}=0 \mathrm{~V}$. Also, it is reported that the oxidation of first nitrogen can be via Langmuir-Hinshelwood (LH) or Eley-Rideal (ER) mechanism ${ }^{8,19}$. In the LH mechanism, the $\mathrm{OH}^{-}$ion is captured by electron deficient Carbon (C) site adjacent to the $\mathrm{Mn}$ site with $\mathrm{N}_{2}$ preadsorbed on the Mn site (formed $* \mathrm{~N}_{2} * \mathrm{OH}$ ), following the formation of $* \mathrm{NNO}$ or $* \mathrm{~N}_{2} * \mathrm{O}$ in the next step. After the mentioned step, alternate or distal pathway(s) are followed. In ER mechanism, the $\mathrm{OH}^{-}$ion directly attached with the pre-adsorbed $\mathrm{N}_{2}$ to form $* \mathrm{NNOH}$. We found that the LH mechanism is more promising than ER for the first oxidation of $\mathrm{N}_{2}$ by $1.05 \mathrm{eV}$ energy (step 2 in the Figure SI). Further, the alternate pathway is preferred over distal due to $0.48 \mathrm{eV}$ lower in free energy steps (step 4 in Figure SI). As shown in Figure 1b, the full free energy profile of $\mathrm{N}_{2} \mathrm{OR}$ at applied potential $\mathrm{U}=0 \mathrm{~V}$, equilibrium potential $(1.15 \mathrm{~V})$ and the limiting potential $(1.77 \mathrm{~V})$. At limiting potential $\mathrm{U}=1.77 \mathrm{~V}$, all the steps in free energy profile becomes downhill and exothermic for preparation of nitric acid. At the equilibrium potential (U $=1.15 \mathrm{~V})$, the reactants and products are at equilibrium and the highest uphill step in free energy is a potential determining step, which is used to define thermodynamic overpotential ( $\eta$ ) (limiting potential - equilibrium potential) for $\mathrm{N}_{2} \mathrm{OR}$. Recently, the $\mathrm{TiO}_{2}$ catalyst are theoretically investigated for $\mathrm{N}_{2} \mathrm{OR}$, which shows $\eta=2.08 \mathrm{~V}^{19}$. Similarly, for MnPc catalyst, we 
have confirmed the first step protonation, $* \mathrm{NNO}$ to $* \mathrm{NONOH}$ as the potential determining step and the overpotential $(\eta)$ is only $0.62 \mathrm{~V}$. It is to be noted that, the final step $* \mathrm{NO}_{3} \mathrm{H}$ to free $\mathrm{HNO}_{3}$, which involves the release of nitric acid without a proton/electron transfer does not belong to the $\mathrm{N}_{2} \mathrm{OR}$.

(a)
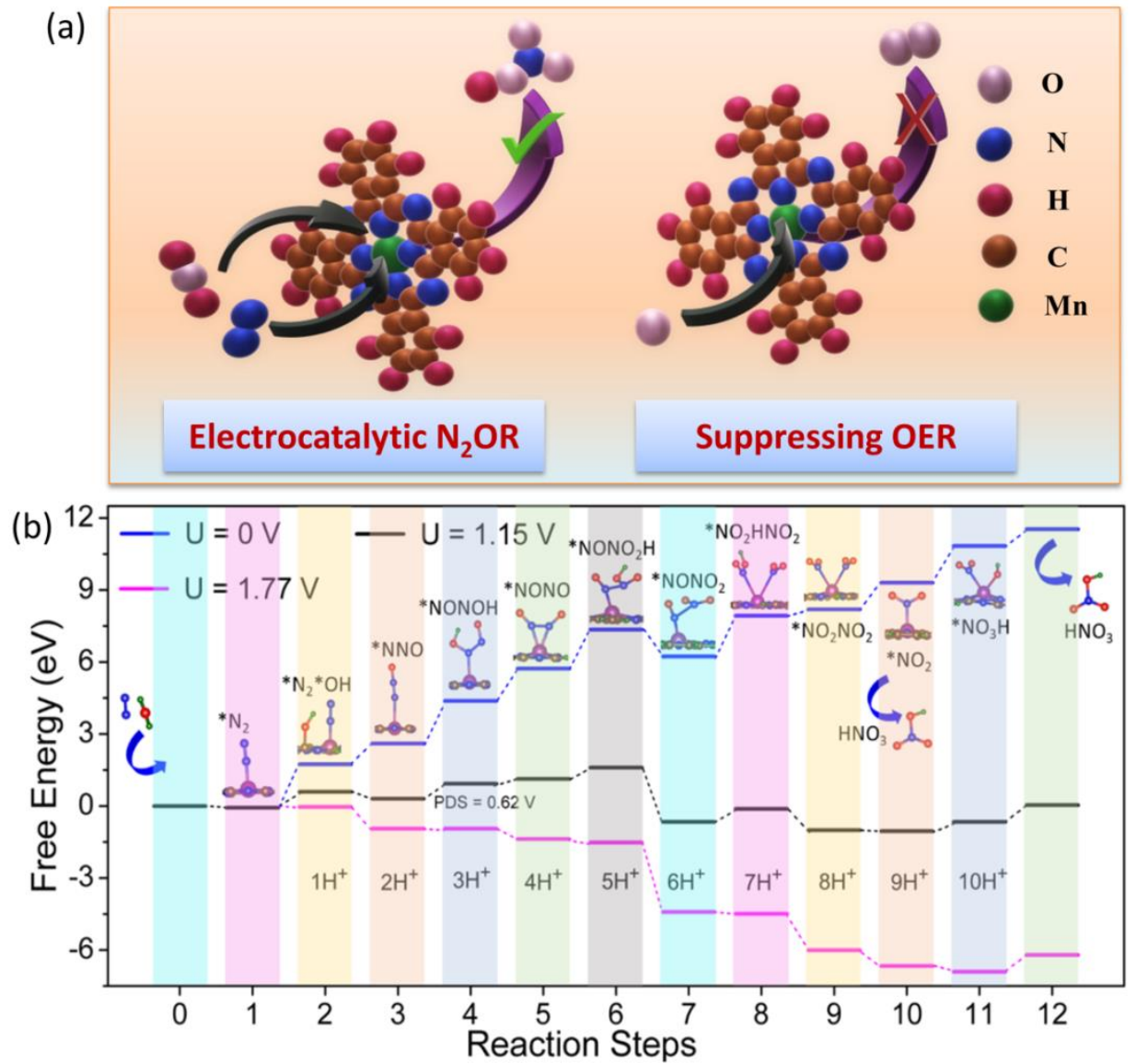

Figure 1: a) Schematic representation of nitric acid synthesis process on the surface of MnPc; $b$ ) Demonstrate the free energy profile of ten electron electrochemical $\mathrm{N}_{2}$ oxidation reaction on MnPc catalyst at applied potential $U=0 \mathrm{~V}, 1.15 \mathrm{~V}$ (equilibrium potential), $1.77 \mathrm{~V}$ (limiting potential). Here PDS indicate the potential determining step. Dotted lines are to guide the eye.

Electrocatalyst synthesis and its characterization: The MnPc HNs were prepared by solvothermal method, where phthalonitrile and manganese acetate are used as reactants with ethylene glycol as solvent medium. The detailed reaction mechanism is demonstrated in the 
Figure 2a. In this reaction, ethylene glycol acts as a nucleophile and it makes an attack to the cyano group present in phthalonitrile molecules. An intermediate product is produced in the reaction which further combines together to form a stable MnPc molecule. To determine the crystal structure and phase purity of MnPc crystal, X-ray diffraction technique (XRD) was used. The XRD pattern (Figure 2b) are well matched with the standard ICDD card no \#02-063-3894 of MnPc with present space group of $\mathrm{P} 2_{1 / \mathrm{c}}{ }^{20}$. The first two peaks at $6.90^{\circ}$ and $9.11^{\circ}$ confirms the formation of $\beta-\mathrm{MnPc}$ structure. All intense XRD planes are indexed as (100), (102), $(002),(\overline{2}$ $02),(\overline{3} 02)$, and $(\overline{104})$ at the $2 \theta$ theta values of $6.90^{\circ}, 9.11^{\circ}, 10.49^{\circ}, 12.50^{\circ}, 18.1^{\circ}$, and $18.52^{\circ}$.
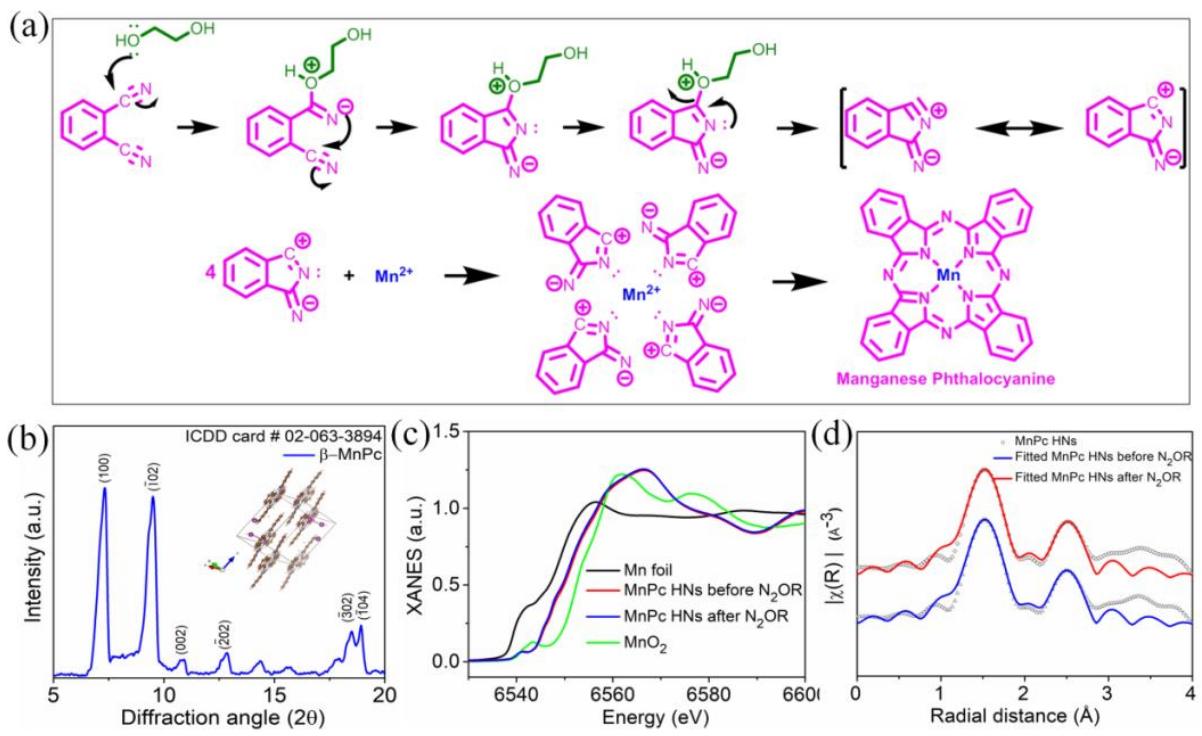

(e)
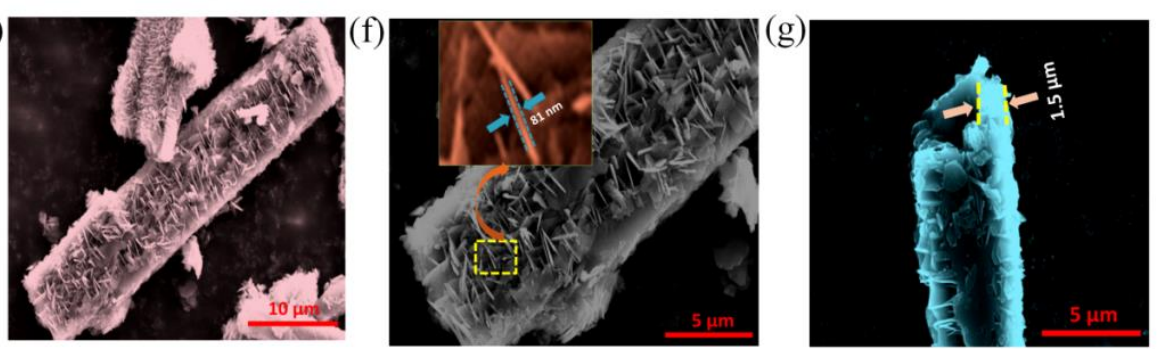

Figure 2:(a) Reaction mechanism for the synthesis of MnPc molecule (b) XRD pattern of MnPc HNs; (c) Normalized XANES spectra at the Mn K-edge; (d) Experimental $\chi(R)$ vs $R$ data of MnPc HNs measured at the Mn K-edge with fitting; (e), (f) \& ( $g$ ) FESEM images of MnPc HNs at different magnifications. 
Fourier transformed infrared spectroscopy (FTIR) technique was performed to examine the chemical bonds present in the MnPc crystal (Figure SI). To study the different type of chemical composition present in $\mathrm{MnPc}$ crystal, X-ray photoelectron spectroscopy (XPS) technique was performed. The survey scan (Figure SI) proves the presence of $\mathrm{Mn}, \mathrm{C}$ and $\mathrm{N}$ atoms in MnPc crystal. The high resolution spectrum of N1s in the XPS spectrum shows the two peaks (Figure SI) at $399.33 \mathrm{eV}$ and $400.42 \mathrm{eV}$ resulting to the pyridinic $-\mathrm{N}$ and pyrrolic- $\mathrm{N}$ present in $\mathrm{MnPc}$. In MnPc, pyridinic nitrogen atoms are attached with carbon atoms and pyrrolic nitrogen atoms are bonded with Mn-metal center. Synchrotron based X-ray absorption nearedge structure (XANES) was performed to study the electronic configuration of manganese in $\mathrm{MnPc}$ electrocatalyst before and after $\mathrm{N}_{2} \mathrm{OR}$ process. Figure 2c shows the normalized XANES spectra of MnPc $\mathrm{HNs}$ before and after $\mathrm{N}_{2} \mathrm{OR}$ electrolysis measured at Mn K-edge along with that of the metal foil and $\mathrm{MnO}_{2}$ standard. It has been observed that the $\mathrm{X}$-ray absorption edge position of $\mathrm{MnPc}$ lies in between $\mathrm{Mn}$ foil and $\mathrm{MnO}_{2}$ and hence the oxidation state of ' $\mathrm{Mn}$ ' in MnPc lies between 0 and $+4{ }^{21,22}$. To study the local coordination environment of the $\mathrm{Mn}$ in MnPc electrocatalyst, extended X-ray absorption fine structure (EXAFS) analysis was carried at $+1.9 \mathrm{~V}$ vs. RHE before and after $\mathrm{N}_{2} \mathrm{OR}$ electrolysis. Figure 2d shows the Fourier-transformed (FT)-EXAFS spectra of the MnPc HNs samples (before and after electrolysis) exhibiting an intense peak at $1.5 \AA$ which can be assigned to the first shell $\mathrm{Mn}-\mathrm{N}$ co-ordination bonds ${ }^{23}$. From the quantitative fitting of Fourier transformed $\mathrm{k}^{2}$ weighted EXAFS (FT-EXAFS) spectra, the obtained co-ordination number of Mn with surrounding nitrogen is four which is almost same during $\mathrm{N}_{2} \mathrm{OR}$ process and prior to it (Figure 2d and Table SI). The FESEM images of MnPc hierarchical nanostructure with different magnifications is shown in Figure 2e-g. In Figure 2e, the microstructure of the MnPc shows a quadrangular shape with average length and 
diameter of $\sim 50 \mu \mathrm{m}$ and $\sim 5 \mu \mathrm{m}$. Furthermore, the detailed microstructure of the MnPc HNs at higher magnification is shown in the Figure 2f, which demonstrates that the micro quadrangular shapes were made by the densely packed nanoflakes. The thickness of the nanoflakes is in the range of $\sim 75$ to $\sim 100 \mathrm{~nm}$. The hollow interior space in the HNs is clearly observed in the Figure $2 \mathrm{~g}$.

Electrocatalytic $\mathrm{N}_{2} \mathrm{OR}$ performance towards nitric acid synthesis: The evaluation of the electrochemical nitric acid synthesis performance was executed in a three electrode setup utilizing chronoamperometry method at constant potentials. The subjected electrolyte $(0.05 \mathrm{M}$ $\mathrm{HCl}$ ) was saturated by effervescing nitrogen or argon gas of ultra-high pure grade. (Figure SI and details explanation in electrochemical set-up).
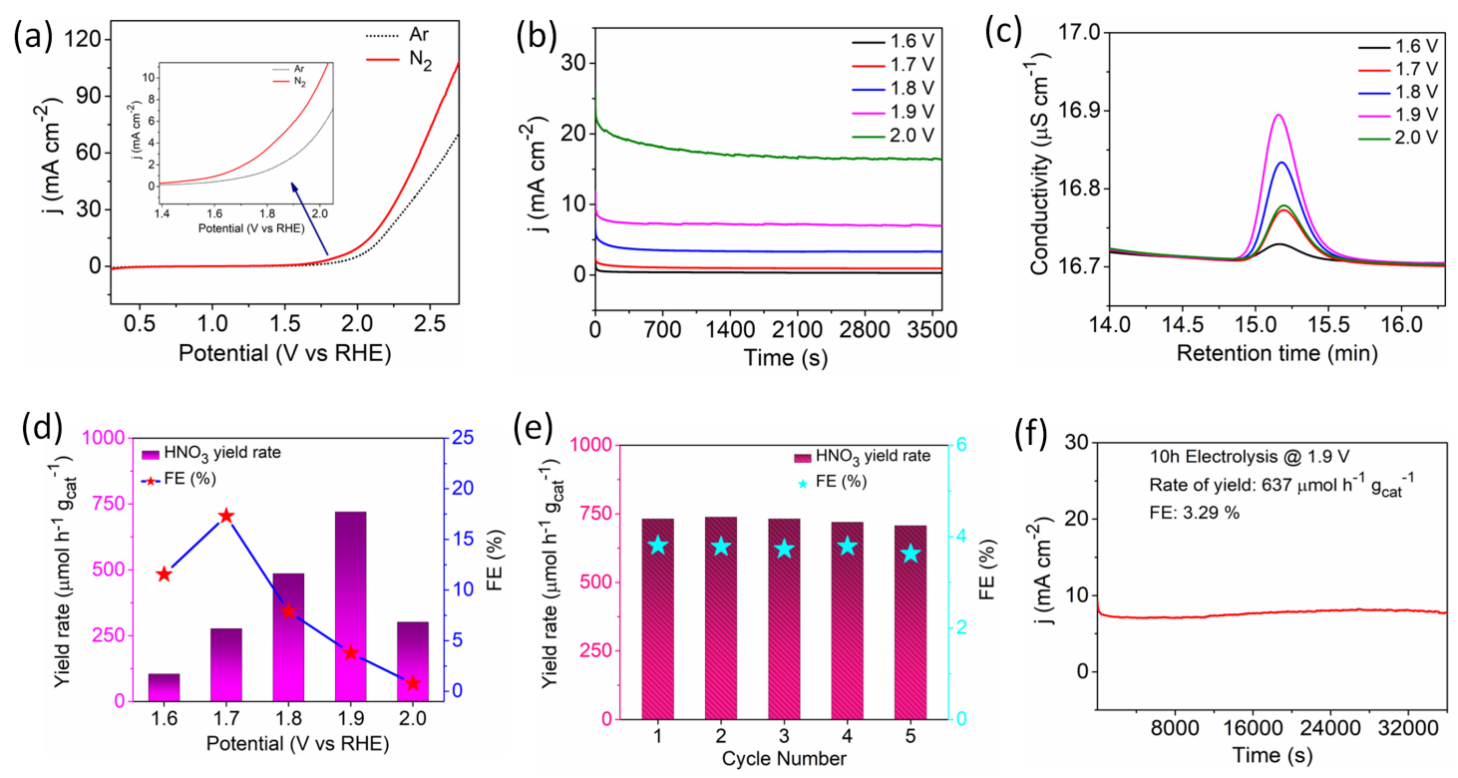

Figure 3:(a) LSV profile of MnPc HNs in Ar \& $N_{2}$ saturated $0.05 \mathrm{M} \mathrm{HCl}$ solution; (b) Time reliant current density (j) curves for MnPc HNs at various potential; $(c)$ Ion chromatogram spectra of the electrolytes at different potential after $3600 \mathrm{sec} \mathrm{N}_{2} \mathrm{OR}$ electrolysis; (d) Bar chart of average $\mathrm{HNO}_{3}$ yield rate and corresponding Faradaic efficiency of MnPc HNs at different potential; (e) Recycling stability tests of MnPc HNs for $\mathrm{N}_{2} \mathrm{OR}$ at $1.9 \mathrm{~V}$ vs. RHE for five times; (f) $10 \mathrm{~h}$ durability test for MnPc HNs towards $\mathrm{N}_{2} \mathrm{OR}$ at $1.9 \mathrm{~V}$ vs. RHE in $\mathrm{N}_{2}$ saturated electrolyte 
The electrocatalyst mass were loaded and optimized condition were achieved to precisely determine the faradic efficiency. Linear sweep voltammetry (LSV) was used to initially evaluate the electrocatalytic performance of MnPc HNs. As shown in Figure 3a, the MnPc HNs demonstrates an augmentation in current density in $\mathrm{N}_{2}$ saturated $0.05 \mathrm{M} \mathrm{HCl}$ compared to the $\mathrm{Ar}$ saturated electrolyte, implying the formation of electrochemical nitric acid. The electrocatalysis tests are executed at the potentials of 1.6 to $2.0 \mathrm{~V}$ vs. RHE, the ion chromatograph and chronoamperometry results are exhibited in Figure $\mathbf{3 b}$ and $\mathbf{3 c}$. The peak area attains the maxima at $1.9 \mathrm{~V}$ vs. RHE where the nitric acid yield is $720 \mu \mathrm{mol} \mathrm{h}^{-1} \mathrm{~g}^{-1}$ cat shown in Figure 3d. It is to be noted that at the same potential, nitric acid faradic efficiency is $3.8 \%$, however the dramatically elevated faradic performance of $17.32 \%$ were observed at $1.7 \mathrm{~V}$ vs. RHE. The yield rate of nitric acid almost linearly increases from the potential of 1.6 to $1.9 \mathrm{~V}$ vs RHE., beyond the positive potential, the electrochemical nitric acid synthesis performance drops down due to the enhancement of the competing OER at the higher potential than the $\mathrm{N}_{2} \mathrm{OR}$ in the electrode surface ${ }^{15}$. The sturdy electrochemical activity of MnPc HNs is displayed in the longstanding (10 h) chronoamperometry results in Figure 3f. This can be attributed to the retention of the structural integrity of the crystalline phase of the catalyst during the progress of electrochemical process, the corresponding UV-vis, XRD, and XPS study (Figures SI) of the MnPc HNs confirms the chemical and structural stability of the catalyst during $\mathrm{N}_{2} \mathrm{OR}$ process.

The control experiment was carried out in $0.05 \mathrm{M} \mathrm{HCl}$ without any nitrogen source (argon gas was bubbled, open circuit condition) which resulted in negligible amount of nitric acid production as displayed in ion chromatogram (Figure SI). This clearly shows that the $\mathrm{N}$ element in $\mathrm{HNO}_{3}$ actually emerges for the bubbled $\mathrm{N}_{2}$ gas. To further decipher the source of nitrogen in nitric acid, isotope labelling electrochemical experiments was also carried out by 
bubbling ${ }^{15} \mathrm{~N}_{2}$ gas in the electrolyte. The characteristic singlet peak of ${ }^{15} \mathrm{~N}$ labelled nitric acid where observed in the ${ }^{15} \mathrm{~N}$ NMR spectrum at $\sim 376 \mathrm{ppm}$ (Figure SI) which validates that the oxidation of ${ }^{15} \mathrm{~N}_{2}$ feed gas is solely responsible $\mathrm{HNO}_{3}$ production ${ }^{11}$. The UV-vis absorption spectra of the standard $\mathrm{NO}_{2}^{-}$solution and $\mathrm{N}_{2} \mathrm{OR}$ derived electrolytes at different potential confirm the absence of the $\mathrm{NO}_{2}^{-}$as a by-product during electrocatalytic process as displayed in From Figure SIa-SIb. The primary indicators of industrial application of an electrocatalyst depends broadly on two parameters these are performance repeatability and process stability, as shown in Figure 3e, the MnPc HNs catalyst is relatively stable with consistent performance for five repeat cycle of electrochemical nitric acid production.

From the critical stand point, it is vital to understand the oxygen evolution reaction (OER), a parallel reaction occurring during $\mathrm{N}_{2} \mathrm{OR}$ process ${ }^{24}$, which compete and hinders the efficiency of $\mathrm{N}_{2} \mathrm{OR}$. Therefore, we have studied the possibility of OER on MnPc catalyst using free energy profile (Figure SI). Firstly, we observed that the $\mathrm{OH}$ adsorption on $\mathrm{Mn}$ site of $\mathrm{MnPc}$ (the first intermediate step for OER) ${ }^{25}$ is endothermic with free energy change $(+0.605 \mathrm{eV})$, whereas $\mathrm{N}_{2}$ adsorption is favorable with exothermic free energy change of $-0.069 \mathrm{eV}$. Secondly, we have pinpointed the preferred mechanism to be LH, further estimations reveal whether the adsorbed $\mathrm{OH}$ on $\mathrm{C}$ site can lead to OER or not. It is observed that the free energies of $* \mathrm{~N}_{2} * \mathrm{O}$ and $* \mathrm{~N}_{2} * \mathrm{OOH}$ steps of OER are higher than the $* \mathrm{NNO}$ and $* \mathrm{NONOH}$ steps of $\mathrm{N}_{2} \mathrm{OR}$ respectively. However, both $* \mathrm{OH}$ or $* \mathrm{O}$ on $\mathrm{C}$ site can react with $* \mathrm{~N}_{2}$ to form $* \mathrm{NNO}$, which helps in $\mathrm{N}_{2} \mathrm{OR}$ pathways by suppressing OER on $\mathrm{C}$ site. Also, we have computed the limiting potential $(\mathrm{U}=$ $2.38 \mathrm{~V}$ ) for OER (Figure SI) on Mn site which is very high compared to the limiting potential $(\mathrm{U}=1.77 \mathrm{~V})$ for $\mathrm{N}_{2} \mathrm{OR}$ process. Therefore, we hereby confirm that the $\mathrm{N}_{2} \mathrm{OR}$ is a dominant reaction over OER on both $\mathrm{Mn}$ and $\mathrm{C}$ sites of $\mathrm{MnPc}$ catalyst. Further, we have studied the 
adsorption behavior of $\mathrm{N}_{2}$ on different possible active sites of MnPc as shown in Figure 4a. The free energy change for adsorbed $\mathrm{N}_{2}$ on different sites is obtained in the following order: $\mathrm{Mn}$ ($0.069 \mathrm{eV})>$ pyridinic-N1 $(-0.038 \mathrm{eV})>$ pyrrolic-N2 $(-0.023 \mathrm{eV})>$ pyrrolic-N3 $(-0.017 \mathrm{eV})>$ Carbon $(-0.002 \mathrm{eV})$. It epitomizes the $\mathrm{Mn}$ site of MnPc to play the role of prominent active site for $\mathrm{N}_{2}$ adsorption. The molecular adsorption behavior of $\mathrm{Mn}$ site is correlated with $\mathrm{d}$ band center of $\mathrm{Mn}$ atom ${ }^{26}$ (Figure $\left.\mathbf{4 b - d}\right)$.

(a)

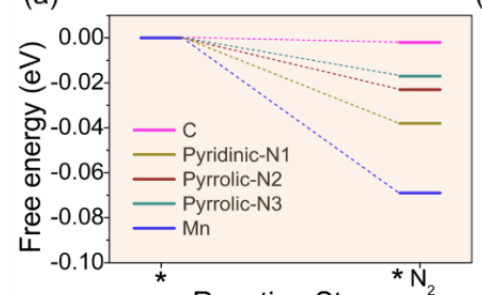

(d)

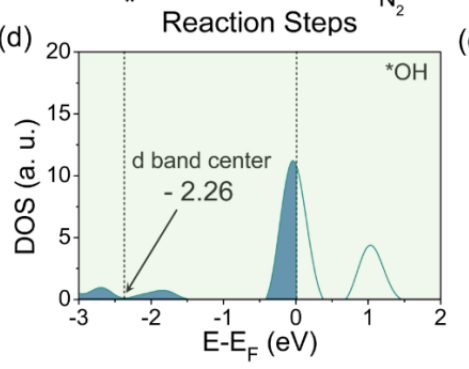

(b)

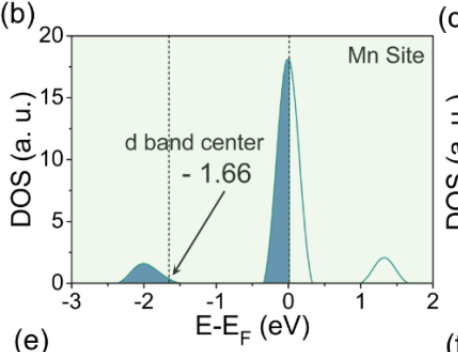

(e)

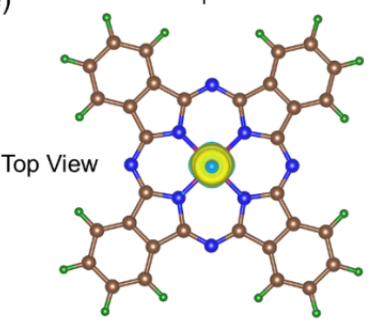

(c)

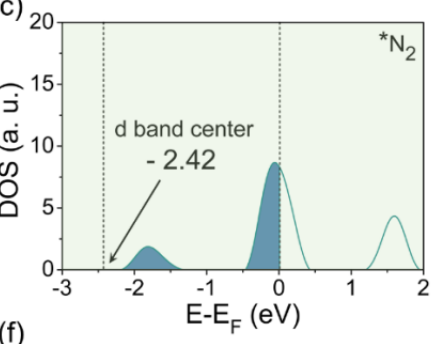

(f)

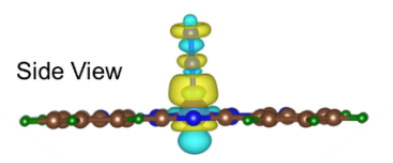

Figure 4 (a) Free energy of $\mathrm{N}_{2}$ adsorption on possible active sites of MnPc. The projected density of states of $d$ orbital for (b) Mn site (c) Mn site after $N_{2}$ adsorption (d) Mn site after OH adsorption. The charge density difference of MnPc after $N_{2}$ adsorption (e) Top view (f) Side view. The Mn, N, O, C, $H$ atoms are denoted with pink, blue, red, wine, and green color sphere respectively. Yellow and blue lobes indicate electron accumulation and depletion, respectively (Isosurface value $=0.005 \mathrm{e} / \mathrm{A}^{3}$ ).

The calculated d-band center of $\mathrm{Mn}$ atom of $\mathrm{MnPc}$ is at $-1.66 \mathrm{eV}$, and after adsorption of $\mathrm{N}_{2}$ and $\mathrm{OH}$ molecules, it is found that the $\mathrm{d}$ band center shifted towards the negative energy and obtained at $-2.42 \mathrm{eV}$ and $-2.26 \mathrm{eV}$ respectively. The higher shift in the $\mathrm{d}$ band center is the reason of exothermic free energy step of $\mathrm{N}_{2}$ adsorption as compared to the endothermic step for $\mathrm{OH}$ 
adsorption on Mn site. It indicates that the required charge transfer occurs from Mn site to adsorbed $\mathrm{N}_{2}$, which is further visualized through charge density difference analysis (Figure 4ef).

Conclusion: In summary, we have developed a strategy towards direct ten-electron oxidation of dinitrogen to nitric acid by MnPc HNs electrocatalyst under ambient conditions. The excellent $\mathrm{N}_{2} \mathrm{OR}$ performances are achieved due to the specific-selectivity, presence of excess number of active sites, repeatability and longstanding sturdy nature of the electrocatalyst. Isotopic labelling experiment has been performed with ${ }^{15} \mathrm{~N}$ nuclear magnetic resonance (NMR) to prove that the purged nitrogen gas is the sole source of $\mathrm{N}$ element in $\mathrm{HNO}_{3}$. The $\mathrm{X}$-ray absorption fine structures (XAFS) confirm that Mn atoms are coordinated to the pyrrolic and pyridinic $\mathrm{N}$ via $\mathrm{Mn}-\mathrm{N}_{4}$ coordination. Density functional theory (DFT) calculations reveal that the Mn site of $\mathrm{MnPc}$ is the prominent active site for $\mathrm{N}_{2}$ adsorption and $\mathrm{N}_{2} \mathrm{OR}$ is a dominant reaction over OER on both $\mathrm{Mn} \& \mathrm{C}$ sites of MnPc catalyst. This research work capitalizes on a new arena of $\mathrm{N}_{2} \mathrm{OR}$ process leading to successful single step nitric acid synthesis using MnPc catalyst via ten electron transfer for the development to attain the near future global goal to make a carbonneutral sustainable society.

\section{Experimental Section}

Materials: All commercially available chemicals were used any additional washing. Phthalonitrile (Sigma-Aldrich), ethylene glycol (Merck), ammonium heptamolybdate tetrahydrate (Merck), manganese acetate (Sigma-Aldrich), and $\mathrm{HCl}$ (Merck). 
Synthesis method: MnPc HNs was prepared by solvothermal process. For the solvothermal method, a precursor solution was prepared by mixing of $1.8 \mathrm{mmol}$ of phthalonitrile, $20 \mathrm{mg}$ of ammonium hepta molybdate tetrahydrate, $0.45 \mathrm{mmol}$ of manganese acetate and $72 \mathrm{ml}$ of ethylene glycol solvent. Then, stir the mixture for 10-15 minutes and stop stirring when nucleation just start and transfer the solution mixture to an $100 \mathrm{ml}$ autoclave Teflon cup. The temperature of the oven was kept at $180{ }^{\circ} \mathrm{C}$ for 22 hours. After the oven cooling, the solution was filtered with using Whatman 41 filter paper. The residue was washed several times with ethanol, $0.1 \mathrm{M} \mathrm{HCl}$ and hot water. Then, the precipitate was dried at $65^{\circ} \mathrm{C}$ for $12 \mathrm{~h}$. Finally, MnPc sample was collected for further used.

Characterization techniques: $X$-ray diffraction technique (XRD) was used to observe the crystal structure and phase purity of synthesized MnPc. XRD analysis of MnPc was done utilizing the Bruker D-8 with advanced Eco X-ray powder diffractometer where the $\mathrm{Cu}-\mathrm{K}_{a}$. was used as a monochromatic radiation with a wavelength value of $0.15404 \mathrm{~nm}$. X-ray tube voltage and current condition were maintained at $40 \mathrm{kV}$ and $25 \mathrm{~mA}$, respectively. X-ray photoelectron spectroscopy (XPS) study of MnPc was done utilizing an OMICRON-0571 framework. FTIR analysis (Shimadzu IRAffinity-1S) was done to see the different type of chemical bond present in $\mathrm{MnPc}$ nanostructures. The morphological observation of synthesis $\mathrm{MnPc}$ was done by using the field emission scanning electron microscope (FESEM) (Thermo Scientific, Apreo-S). All electrochemical nitrogen oxidation analysis was done by CHI 760E instrument.

Electrochemical set-up: All electrochemical nitrogen oxidation processes were done in $0.05 \mathrm{M}$ $\mathrm{HCl}$ solution with purging of ultra high pure nitrogen gas $\left(\mathrm{N}_{2}\right)(99.999 \%)$ gas. Three electrodes setup was used for the nitrogen oxidation reaction $\left(\mathrm{N}_{2} \mathrm{OR}\right)$ process where the catalyst loaded on carbon paper as working electrode, saturated $\mathrm{Ag} / \mathrm{AgCl}$ was used as the reference electrode and 
the counter electrode was platinum wire. Before starting any experiment, nitrogen gas was purged for 30 minutes to saturate in the electrolyte solution. All applied potential values were converted to the reversible hydrogen electrode (RHE).

\section{Author information}

\section{Corresponding author:}

*Email: uttam.indchem@vidyamandira.ac.in

FAX: 2654-1123; Phone: 9133 26549181

\section{ORCID}

Uttam Kumar Ghorai: 0000-0003-0537-598X

Notes: UKG, AA and SP have filed an Indian Patent application (202131029797) regarding the electrochemical synthesis of nitric acid under ambient conditions. The remaining authors declare no competing interests.

\section{AUTHOR CONTRIBUTIONS}

UKG conceived the idea and designed the experiments. BG and AA synthesized the catalyst and performed the XRD, FTIR, UV-vis. AA and SP carried out all the electrochemical measurements and analyzed the results. SK and RT performed the theoretical (DFT) calculations. RT, SK, AA and SP analyzed the DFT results. AA and UKG wrote the original manuscript. All authors contributed to write the final version of the manuscript. UKG supervised the project. 


\section{ACKNOWLEDGEMENTS}

UKG acknowledges the Teachers Associateship for Research Excellence (TARE) scheme (TAR/2018/000763) of SERB, Govt. of India for research grant. UKG thanks to DBT star college scheme (BT/HRD/11/036/2019) for funding. UKG also acknowledges Science \& Technology and Biotechnology Department, Govt. of West Bengal for providing the financial support [199 (Sanc.)/ST/P/S\&T/6G-12/2018]. R.T. thanks Board of Research in Nuclear Sciences (BRNS), India, for the financial support (Grant Nos. 37(2)/20/14/2018-BRNS/37144). The authors thank High Performance Computing Center, SRM IST for providing the computational facility. The authors acknowledge Dr. D. Bhattacharya and Dr. S. N Jha for the XANES experiment. The authors thank Dr. S. Mandal and Mr. A. Gain for their technical assistance.

\section{References:}

1. Chen, J. G. et al. Beyond fossil fuel-driven nitrogen transformations. Science (80-. ). 360, (2018).

2. Liu, Y. et al. Pothole-rich ultrathin $\mathrm{WO}_{3}$ nanosheets that trigger $\mathrm{N} \equiv \mathrm{N}$ bond activation of nitrogen for direct nitrate photosynthesis. Angew. Chemie - Int. Ed. 58, 731-735 (2019).

3. Brown, K. A. et al. Light-driven dinitrogen reduction catalyzed by a CdS:nitrogenase MoFe protein biohybrid. Science (80-. ). 352, 448-450 (2016).

4. Wang, Y., Li, T., Yu, Y. \& Zhang, B. Electrochemical synthesis of nitric acid from nitrogen oxidation. Angew. Chemie Int. Ed. (2021) doi:10.1002/anie.202115409.

5. Li, T. et al. Ru-doped Pd nanoparticles for nitrogen electrooxidation to nitrate. ACS Catal. 
14032-14037 (2021) doi:10.1021/acscatal.1c04360.

6. Wang, Y., Yu, Y., Jia, R., Zhang, C. \& Zhang, B. Electrochemical synthesis of nitric acid from air and ammonia through waste utilization. Natl. Sci. Rev. 6, 730-738 (2019).

7. Zhang, L. et al. A janus $\mathrm{Fe}-\mathrm{SnO}_{2}$ catalyst that enables bifunctional electrochemical nitrogen fixation. Angew. Chemie - Int. Ed. 59, 10888-10893 (2020).

8. Dai, C., Sun, Y., Chen, G., Fisher, A. C. \& Xu, Z. J. Electrochemical oxidation of nitrogen towards direct nitrate production on spinel oxides. Angew. Chemie - Int. Ed. 59, 9418$9422(2020)$.

9. Han, S., Wang, C., Wang, Y., Yu, Y. \& Zhang, B. Electrosynthesis of nitrate via the oxidation of nitrogen on tensile-strained palladium porous nanosheets. Angew. Chemie Int. Ed. 60, 4474-4478 (2021).

10. Zhang, Y. et al. Electrocatalytic fixation of $\mathrm{N}_{2}$ into $\mathrm{NO}_{3}{ }^{-}$: Electron transfer between oxygen vacancies and loaded $\mathrm{Au}$ in $\mathrm{Nb}_{2} \mathrm{O}_{5}^{-}$: Xnanobelts to promote ambient nitrogen oxidation. J. Mater. Chem. A 9, 17442-17450 (2021).

11. Fang, W. et al. Boosting efficient ambient nitrogen oxidation by a well-dispersed Pd on MXene electrocatalyst. Chem. Commun. 56, 5779-5782 (2020).

12. Kuang, M. et al. Efficient nitrate synthesis via ambient nitrogen oxidation with Ru-doped $\mathrm{TiO}_{2} / \mathrm{RuO}_{2}$ electrocatalysts. Adv. Mater. 32, 1-7 (2020).

13. Lan, J. et al. Nanoporous $\mathrm{B}_{13} \mathrm{C}_{2}$ towards highly efficient electrochemical nitrogen fixation. Small 17, 1-7 (2021).

14. Guo, Y. et al. Electrochemical nitrate production via nitrogen oxidation with atomically 
dispersed $\mathrm{Fe}$ on N-doped carbon nanosheets . ACS Nano (2021) doi:10.1021/acsnano.1c08109.

15. Ghorai, U. et al. Scalable production of cobalt phthalocyanine nanotubes: efficient and robust hollow electrocatalyst for ammonia synthesis at room temperature. ACS Nano $\mathbf{1 5}$, $5230-5239$.

16. Murmu, S. et al. Unveiling the genesis of the high catalytic activity in nickel phthalocyanine for electrochemical ammonia synthesis. J. Mater. Chem. A 9, 1447714484 (2021).

17. He, C. et al. Identification of $\mathrm{FeN}_{4}$ as an efficient active site for electrochemical $\mathrm{N}_{2}$ reduction. ACS Catal. 9, 7311-7317 (2019).

18. Mukherjee, M., Samanta, M., Banerjee, P., Chattopadhyay, K. K. \& Das, G. P. Endorsement of manganese phthalocyanine microstructures as electrocatalyst in ORR: Experimental and computational study. Electrochim. Acta 296, 528-534 (2019).

19. Anand, M., Abraham, C. S. \& Nørskov, J. K. Electrochemical oxidation of molecular nitrogen to nitric acid-towards a molecular level understanding of the challenges. Chem. Sci. 12, 6442-6448 (2021).

20. Wang, Z. \& Seehra, M. S. Ising-like chain magnetism, arrhenius magnetic relaxation, and case against 3D magnetic ordering in $\beta$-manganese phthalocyanine (C32H16MnN8). J. Phys. Condens. Matter 28, (2016).

21. Di Castro, V. \& Polzonetti, G. XPS study of MnO oxidation. J. Electron Spectros. Relat. Phenomena 48, 117-123 (1989). 
22. Chen, M. et al. Atomically dispersed $\mathrm{MnN}_{4}$ catalysts via environmentally benign aqueous synthesis for oxygen reduction: mechanistic understanding of activity and stability improvements. ACS Catal. 10, 10523-10534 (2020).

23. Li, J. et al. Atomically dispersed manganese catalysts for oxygen reduction in protonexchange membrane fuel cells. Nat. Catal. 1, 935-945 (2018).

24. Man, I. C. et al. Universality in oxygen evolution electrocatalysis on oxide surfaces. ChemCatChem 3, 1159-1165 (2011).

25. Kapse, S., Janwari, S., Waghmare, U. V. \& Thapa, R. Energy parameter and electronic descriptor for carbon based catalyst predicted using QM/ML. Appl. Catal. B Environ. 286, 119866 (2021).

26. Hammer, B. \& Nørskov, J. K. Theoretical surface science and catalysis—calculations and concepts. Adv. Catal. 45, 71-129 (2000). 